\section{Development of occupational therapy in Grangegorman hospital, Dublin: 1934-1954}

\section{Development of occupational therapy}

\author{
Rebecca Cahill
}

School of Allied Health, Faculty of Education and Health Sciences, University of Limerick, Limerick, Ireland, and

Judith Pettigrew
School of Allied Health and Health Research Institute, Faculty of Education and Health Sciences, University of Limerick, Limerick, Ireland

Received 14 October 2019

Revised 13 January 2020 Accepted 10 February 2020

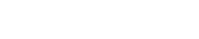

\begin{abstract}
Purpose - In the early to mid-twentieth century, psychiatrist-led occupational therapy departments emerged in Irish psychiatric hospitals. This marked a transition towards establishing rehabilitative services in institutional settings. This paper aims to examine the development of occupational therapy in Grangegorman Mental Hospital and its auxiliary hospital, Portrane Mental Hospital from 1934-1954.

Design/methodology/approach - Historical documentary research methods were used to analyse primary source data from Grangegorman Committee Minutes, Inspector of Mental Hospital Reports, Boroughs of Mental Hospitals, Department of Foreign Affairs documents and newspaper archives. The archival data was analysed using both a chronological and thematic approach.

Findings - The main key event emerged in 1935 when four Grangegorman nursing staff were sent to Cardiff Mental Hospital to undergo a six month training course in occupational therapy. The following themes emerged - "establishing occupational therapy in Grangegorman and Portrane"; "the role of shortcourse trained nursing staff in providing occupational therapy services" and "therapeutic rationales vs hospital management rationales".

Originality/value - This study throws light on the early practitioners of occupational therapy in Grangegorman and highlights the complexities of occupational therapy's role origins in mid-twentieth century Ireland. In line with contemporaneous psychiatric hospitals, the occupational therapy activities promoted in Grangegorman were mainly handicraft or productivity based. The absence of patients' voices means there are limitations to determining the therapeutic nature of this early occupational therapy service.
\end{abstract}

Keywords Ireland, Mental health, History of occupational therapy

Paper type Research paper

\section{Introduction}

Reflecting on the history of a profession contextualises its contemporary practice and aids its continuing development (Higgs et al., 2004). Occupational therapy is a relatively young

(C) Rebecca Cahill and Judith Pettigrew. Published in Irish Journal of Occupational Therapy. Published by Emerald Publishing Limited. This article is published under the Creative Commons Attribution (CC BY 4.0) licence. Anyone may reproduce, distribute, translate and create derivative works of this article (for both commercial and non-commercial purposes), subject to full attribution to the original publication and authors. The full terms of this licence may be seen at http://creativecommons.org/licences/by/4.0/legalcode

The authors would like to thank Brian Donnelly, Senior Archivist in the National Archives of Ireland, for his guidance with sourcing the archival material used in this study. 
IJOT

48,1

profession and its history has been well-documented in countries such as the USA (Anderson and Reed, 2017; Quiroga, 1995), Canada (Friedland, 2011) and the UK (Wilcock, 2002). This study adds to research exploring the history of occupational therapy in Ireland[1] (Dunne et al., 2018a; Lynch and Pettigrew, 2014; Pettigrew et al., 2017; Prendiville and Pettigrew, 2015). Specifically, this study explores the development of occupational therapy in Grangegorman Mental Hospital[2] and its auxiliary hospital, Portrane Mental Hospital. These hospitals catered for the Dublin area and during their population peak in the 1950s, had a combined population of over 3,500 patients (Reynolds, 1992).

\section{Early occupational therapy in mental health}

Occupational therapy was formally established by the founding of the National Society for the Promotion of Occupational Therapy in Clifton Springs, New York, in 1917 (Barker Schwartrz, 2003; Peloquin, 1989). The discipline was influenced by the diverse range of backgrounds of its founders in psychiatry, arts and crafts, nursing and architecture (Peloquin, 1991a; Peloquin 1991b), and by movements such as the mental hygiene movement, arts and crafts movement, settlement house movement, and the need to rehabilitate injured World War I soldiers (Wilcock, 2002). The moral treatment movement of the nineteenth century and its premise that participation in a diverse range of occupations could help restore a person to a healthier mind, was particularly influential in occupational therapy's development in mental health settings (Kielhofner, 2009; Peloquin, 1989). Founding figures Dr William Rush Dunton and Eleanor Clarke Slagle were pioneers in establishing occupational therapy within mental health institutions in the USA during the 1920s. They advocated for the grading of patient activities in self-care, physical activity, productive and handcraft activities (Barker Schwartrz, 2003).

In the UK, the first occupational therapy department was established by psychiatrist David Henderson at Gartnavel Royal Hospital, Scotland, in 1919 (Wilcock, 2002). Occupational therapy in psychiatric hospitals became more widespread in the UK following several study tours organised by the Royal-Medico-Psychological Association (RMPA) to German and Dutch psychiatric hospitals between 1929 and 1934 (Hall, 2016). Members of the study tours were particularly impressed by the occupational therapy practice in Santpoort Mental Hospital, The Netherlands and also in Dr Simon's Gütersloh Hospital in Germany, where the visitors observed over 90 per cent of patients engaged in productive activities (Board of Control, 1933). The 1933 Memorandum on Occupation Therapy for Mental Patients advocated for an institution-wide approach to the introduction of occupational therapy in UK hospitals, through the employment of existing staff and the addition of technicians and occupational therapists (Board of Control, 1933, p. 14). The first occupational therapy training school was established at Dorset House, Clifton Down, Bristol in 1930 by Elizabeth Casson, previously a member of the RMPA study tours (Hall, 2016). The further establishment of the Scottish Association of Occupational Therapists in 1932 and the Association of Occupational Therapists (AOT) in 1936 (covering England, Wales and Northern Ireland), promoted educational standards and the profession throughout Britain in the 1930s (Wilcock, 2002).

\section{Early occupational therapy in Ireland}

Following centuries of British colonial rule, Ireland gained its independence and became the Irish Free State in 1922. It held dominion status until a new constitution was written in 1937 and the country transitioned to its current status as the Republic of Ireland in 1949 (Ferriter, 2004). From the 1930s to 1950s there was relative political stability in Ireland, owing to the general dominance of the new Fianna Fáil party in government (Killeen, 2012). Everyday life in Ireland 
was marked by persistent economic hardship influenced by Ireland's strive for economic selfsufficiency, its reliance on small-scale farming, high tariff regimes during the Economic War[3] (1932-1938) and supply shortages during World War II (Ferriter, 2004; Killeen, 2012).

The Irish mental healthcare system and mental hospitals remained largely unchanged from how they operated under British rule (Brennan, 2014; Gibney, 2017). While the Roman Catholic Church pervaded Irish society and was deeply involved in politics, general healthcare and education, it did not become systematically involved in mental healthcare services (Kelly, 2016). This meant the majority of mental hospitals continued to be state run. The low priority status of mental healthcare within the Irish government meant that there were limited improvements to conditions in mental hospitals at a time when the hospital admissions continued to rise (Kelly, 2016). By the late 1950s, Ireland had the highest rate of psychiatric hospitalisations in the world (Brennan, 2014; Walsh, 1968). This stemmed from various social, political and economic factors, some of which included the reconfiguration of family structures, the large scale employment provided by the local mental hospitals, ongoing economic hardship, decreased community tolerance for mental illness, continued expansion of hospital infrastructure and limited governmental support other than to provide institutional care (Brennan, 2014; Kelly, 2016). Until the beginning of deinstitutionalisation from the mid-1960s onwards, many people admitted to mental hospitals in Ireland during the early twentieth century faced the prospect of spending the rest of their lives within its institutional walls (Kelly, 2016).

Amid the bleak and overcrowded conditions of Irish mental hospitals, efforts were made to increase the range of meaningful activity available to patients (Pettigrew et al., 2017). Occupation had been used in a curative way in Irish asylums during the nineteenth and early twentieth century, mainly in the form of recreation, sports and work (Prendiville and Pettigrew, 2015). However, as will be highlighted below not all occupation was therapeutic.

The first appearance of the term "occupational therapy" in Irish media was in a newspaper article about Peamount Sanatorium, Dublin, September 1930 (Irish Times, 1930). Similar to the international field (Friedland, 2011), patronage by psychiatrists was an important factor in the development of occupational therapy in Ireland (Dunne et al., 2018b). The findings of the British RMPA study tours influenced Dr Eamon O'Sullivan, Resident Medical Superintendent (RMS) who established an occupational therapy department in the 1930s in Killarney Mental Hospital, based in part on Dr Simon's principles (O'Sullivan, 1955). Here, occupational therapy was facilitated by technically skilled nursing staff and engaged 85-90 per cent of patients in a range of handicrafts, work, recreational and reeducational activities (O'Sullivan, 1955). Psychiatrist Dr Ada English developed occupational therapy during the 1930s in St. Brigid's Hospital, Ballinasloe, Co. Galway where she advocated for the gainful employment of patients in recreational activities and productive activities such as farmwork, trades and handicrafts (Kelly, 2014). Although there is evidence of therapeutic underpinnings in these public hospitals, critical reflection has questioned the extent to which the productive activities reflected unpaid work to keep hospital costs down (Kelly, 2016). Hall (2016, p. 314) also notes that "a pattern of regular daily activity was seen as conducive to less disturbing behaviour".

Comparatively later than its international counterparts, professionally qualified occupational therapists only began to practice in Ireland in the late 1940s (Pettigrew et al., 2017). In the privately run St. Patrick's Hospital, Dublin, RMS Norman Moore employed Olga Gale to establish an occupational therapy Department in 1946 (Dunne et al., 2018b). Gale was not a registered member of AOT but had completed two years of the Dorset House School of Occupational Therapy. Professionally qualified occupational therapist Margret Sinclair was later employed for a brief period in 1952 (Dunne et al., 2018b). In contrast, to

Development of occupational therapy 
public hospitals, which were generally less resourced and funded (Hall, 2016), patients did not carry out domestic work in St. Patrick's Hospital. The early occupational therapy practice in the hospital involved craft-based and social activities, which was congruent with the international philosophy of occupational therapy at the time (Duune et al., 2018b). The establishment of St. Joseph's College of Occupational Therapy in Dún Laoghaire in 1963 and the founding of the Irish professional body of the Association of Occupational Therapists of Ireland (AOTI) in 1965 marked the beginning of the professional era of occupational therapy in Ireland (Pettigrew et al., 2017).

\section{Grangegorman hospital}

The development of occupational therapy in Grangegorman is an unfolding story, which this study aims to contribute to (Kelly, 2016; Reynolds, 1992). Grangegorman Mental Hospital, originally known as the Richmond Asylum until 1921, was the first public psychiatric asylum in Ireland, opening in Dublin in 1815 and operating as a psychiatric hospital facility until 2013 (Fuller Torrey and Miller, 2001; O’Brien, 2013). An extension of the asylum was built in Portrane, North Dublin in the mid-1890s (Kelly, 2007). In line with psychiatric institutions countrywide, Grangegorman's numbers increased drastically throughout the early to mid-twentieth century resulting in rampant overcrowding and limited resources (Reynolds, 1992). In 1930, Grangegorman was under the charge of RMS Dr John O'Conor Donelan (Reynolds, 1992). The daily care of the patients was overseen by nursing staff who had undergone three years training (Brennan, 2014). Similar to its contemporary hospitals, occupational engagement in Grangegorman served both curative and hospital management purposes (Reynolds, 1992). The Inspectors of Mental Hospitals mentioned recreational activities such as cinema performances, dances, outdoor team sports and work activities such as laundry, kitchen and farm work in their annual reports of Grangegorman in the early 1900s (O'Shea and Falvey, 1996; Reynolds, 1992).

In Reynold's (1992) historical overview of Grangegorman, "occupational therapy" is first referenced in the year 1934. As it was not possible to access Grangegorman Committee Minutes after 1960 due to National Health Service Executive (HSE) data restrictions, this study focuses on the first 20 years of how the practice of occupational therapy developed in Grangegorman hospital from 1934-1954.

\section{Methodology}

Historical documentary methods are a set of techniques used to categorise, investigate and interpret written documents (Payne and Payne, 2004). In line with similar studies (Prendiville and Pettigrew, 2015; Sedgwick et al., 2007), historical documentary methods were used to analyse the archival documents in this study. An interpretivist epistemological stance was taken with the aim to capture multiple viewpoints across the documentary sources and understand the authors' written communication within its historical context (Dunne et al., 2015).

\section{Data collection}

Primary source data creates original perspectives on past events (McDowell, 2002) and help portray how situations evolve over time (Cohen et al., 2007). For these reasons the data was comprised of primary source documents as outlined in Table I. 


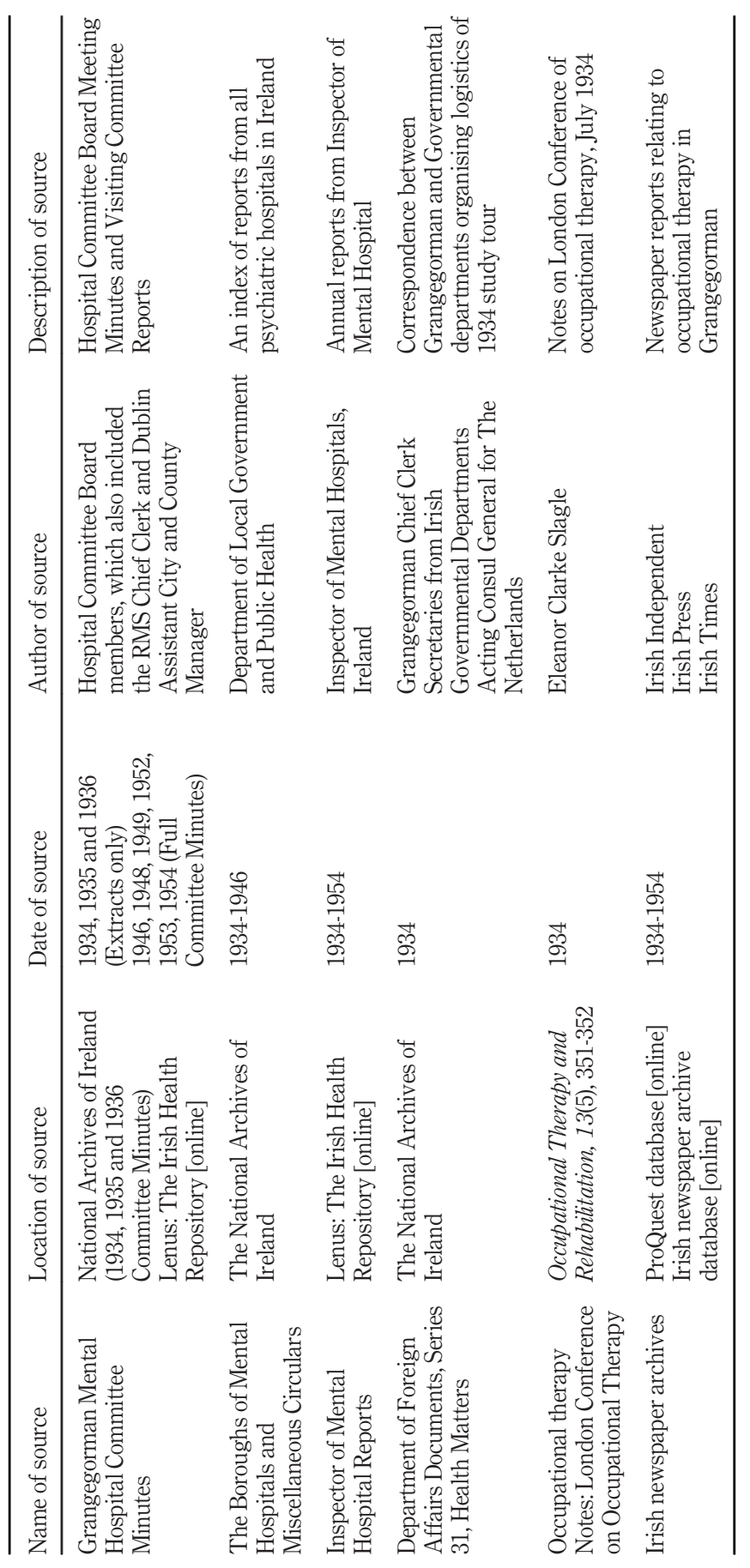

Development of occupational therapy

73

Table I. Documentary sources 
IJOT

48,1

\section{Quality of historical documents}

The four interdependent criteria of authenticity, credibility, representativeness and meaning were used to assess the quality of the archival documents (Scott, 1990). Regarding authenticity, the data sources included published official governmental reports, hospital archives and newspapers archives - all public documents lending strong support to their genuineness (Scott, 1990).

Credibility involves taking the standpoint of the author to assess if what is documented is sincere and accurate (Scott, 1990). The Grangegorman Committee were public figures, mostly male Dublin County or Dublin City Councillors - who were involved in the financial and operational management of the hospital. They also carried out regular visiting committee inspections (Reynolds, 1992). The Inspectors of Mental Hospitals were appointed on a statutory basis and their annual reports provided a more general overview of hospital proceedings (Brennan, 2014). It has been argued that official reports were at times deliberately misleading to present a picture of law and order to central government (Prior, 2004). This consideration was kept to the fore and each archival document, including the newspaper reports, was scrutinised with a degree of scepticism (Dunne et al., 2015).

Access to the Grangegorman Committee Minutes is governed by the HSE and the National Archives of Ireland (Cavalli et al., 2019). HSE data restrictions limited full access to the Grangegorman Committee Minutes from 1934-1954. To enhance representativeness, multiple primary data sources were used to triangulate the data for accuracy and minimise potential distortion from single data sources (Salkind, 2010). To address the meaning of the documents, consideration was given to the perspectives of the authors and their intended readers (Payne and Payne, 2004). Specific uncertainties with handwriting legibility and document terminology were cross-checked with a Senior Archivist at the National Archives of Ireland. At the time of the research the first author was a student and the second author was the research supervisor. Reflexivity was addressed by ongoing critical reflection (Berger, 2013), considering potential bias due to the occupational therapy background of the authors (the second author also has backgrounds in history and social anthropology).

\section{Data analysis}

Both chronological and thematic analysis were used in line with McDowell's (2002) recommendation that using both methods can help contextualise snapshots of history. A preliminary timeline of events was drawn up to get a sense of the historical events as they unfolded. Braun and Clarke's (2006) six-step guide for thematic analysis was used to identify, analyse and report patterns within the archival documents. Phase 1 involved familiarisation with the data and transcribing the data into a Word Document. Phase 2 comprised of coding the data. Codes were grouped into initial themes (Phase 3) and then reviewed for consistency and refined (Phase 4). Following this, the themes were defined and named (Phase 5). Finally, phase six involved consolidating the findings of the final three themes and presenting the information into the written format below. There were ongoing critical discussions among the authors throughout the process, reflecting on the meaning and representation of the data within its historical context.

\section{Ethical considerations}

At present there is no standard protocol in Ireland for the research of historical mental health archival data, meaning that access to data is generally strict (Cavalli et al., 2019). Ethical approval was not required for this study as the data analysed came from documents within the public domain. As illustrated in Table I, archival data was sourced from freely available newspaper websites, Lenus (the online Irish health repository) and publically 
available documents in the National Archives of Ireland. Additionally, small excerpts of the 1934-1936 Grangegorman Committee Minutes were made available by the HSE Mental Health Administration upon request, with the omission of any patient identifiers. No patient names were ever viewed during the research process and the individuals named in this study were from newspaper archives or the publically available Committee Minutes. A core consideration of this research was that the documents indirectly concerned the care of vulnerable people, whom may have living relatives (Lusk, 1997). Utmost effort was made to ensure data was treated with respect and sensitivity (Wiener and Gilliland, 2011).

Development of occupational therapy

\section{Findings}

\section{Establishing occupational therapy in Grangegorman and Portrane}

Thematic analysis pointed to three main influences in Grangegorman's development of occupational therapy - the Grangegorman Hospital Committee, the Irish State Government and international occupational therapy practices. The first key event in Grangegorman's establishment of occupational therapy was Grangegorman's RMS, Dr O'Conor Donelan's attendance at the London Conference on occupational therapy in July 1934 (O'Conor Donelan, 1934). Guest speakers at this conference included occupational therapy pioneering figures Eleanor Clarke Slagle and Dr Elizabeth Casson (Clarke Slagle, 1934). O'Conor Donelan provided feedback to the Grangegorman Hospital Committee Board, on Eleanor Clarke Slagle's "interesting lecture" on the benefits of occupational therapy in mental health institutions in the USA (O'Conor Donelan, 1934, p. 589). He referred to the relative cost effectiveness of establishing occupational therapy, which he described was of benefit to "both patients and institutions" (O'Conor Donelan, 1934, p. 589).

A special sub-committee was formed by the Grangegorman Hospital Committee Board to carry out a study tour of mental hospitals in the UK, The Netherlands and Belgium to investigate their practice of occupational therapy (Irish Free State. Department of Foreign Affairs, 1934; Irish Independent, 1934; Irish Press, 1934). The Grangegorman Hospital Committee corresponded with the Minister of Local Government and Public Health and the Minister of External Affairs to organise the logistics of the tour with the international bodies (Irish Free State. Department of Foreign Affairs, 1934). The study tour took place in autumn 1934 and the sub-committee were impressed with the running of occupational therapy in Santpoort Mental Hospital, The Netherlands and in Cardiff Mental Hospital, Wales (O'Conor Donelan, 1934; Reynolds, 1992). A central message from the tour was the need to develop occupational therapy in Grangegorman with "trained, experienced teachers aiming at the active employment of about 90 per cent of their patients" (Irish Independent, 1934, p. 8).

Following the study tour, Dr O'Conor Donelan corresponded with the Medical Superintendent of Cardiff Mental Hospital to request staff training in occupational therapy (O’Conor Donelan, 1935). In March 1935, Nurse Mary Fox and Attendant James Lea were sent from Grangegorman to Cardiff Mental Hospital for six months training, followed by two more nurses Mary Bergin and Francis Norton in July 1935 (Grangegorman Committee Minutes, 1935).

\section{Role of short-course trained nursing staff in providing occupational therapy services}

By October 1935, Nurse Mary Fox was overseeing the female occupational therapy department in Grangegorman while Attendant James Lea was overseeing the male occupational therapy department in the auxiliary Portrane Mental Hospital (Grangegorman Committee Minutes, 1935). The original aim of the Hospital Committee was that Grangegorman and Portrane would be equally catered for in terms of occupational therapy services (Grangegorman Committee Minutes, 1935, p. 607). This suggests that Nurse Mary Bergin was likely appointed to Portrane's female occupational therapy department and 
IJOT

48,1

Attendant Francis to Grangegorman's male occupational therapy department, although no evidence confirming this was found. According to an Irish Times expenditure report, three nurses and two attendants were registered on the Grangegorman payroll (which included Portrane) as "Occupational Therapy Officers" in January 1937 (Irish Times, 1937a, p. 8).

There were several other occupational therapy staff mentioned in the Committee Minutes throughout the 1940s and early 1950s, including Attendant John Buckley, Nurse M. Breslin, Nurse C. Hughes and Officer J. Hagen. There may have been other nursing staff providing occupational therapy who were not named in the documents searched. Praise from the Visiting Committees of the occupational therapy staff and their service was a pattern, which emerged in the documents:

Visiting the Occupational Therapy rooms, we were shown some magnificent samples of rugs, etc., made by the patients and which reflect great credit on Miss Fox, her assistant instructors and the patients themselves (Grangegorman Visiting Committee, 1952, p. 1145).

A notable finding in this study was the role of the Grangegorman occupational therapy nursing staff in the establishment and running of the Irish Occupational Therapy Association (IOTA) (Irish Press, 1952). The IOTA was founded in March 1951 by Edward C. Fanning, an art graduate who worked as an early occupational therapist in Dublin sanatoriums after undergoing a short occupational therapy course in St. Laurence's Hospital (a former general medical hospital in Dublin) (Fanning, 1951; Foy, 1963, p. 6; O'Malley, 1988). The formation of IOTA in 1951, took place in the same year as international discussions were taking place at the AOT Congress in London, regarding the formation of a world federation of occupational therapists. In a letter to the Irish Independent on 27 June 1951, Fanning stated that a late invitation had prevented the IOTA from attending this congress. Susan Yorkbell was the sole Irish person to attend and according to Fanning, she did so in a personal capacity as an AOT member (Fanning, 1951; Irish Independent, 1951). The World Federation of Occupational Therapists (WFOT) was formed in 1952 by representatives from 10 national associations - the USA, the UK, Canada, South Africa, Sweden, New Zealand, Australia, Israel, India and Denmark (World Federation of Occupational Therapists, 2019). Member countries had to have occupational therapy associations and these associations had to be vouched for by associations from three other countries (WFOT, 2019). Subsequently, IOTA did not become a member of WFOT.

Despite their lack of international links, the IOTA were active locally and held a meeting in Grangegorman on 11 March 1952 at which hospital occupational therapy staff were reelected to the following positions - Mary Fox as President, J. Hagen as vice-chairman, M. Breslin as secretary and John Buckley as treasurer (Irish Press, 1952, p. 7). Brief newspaper coverage of this meeting referenced "plans for a four-year course in occupational therapy and an officially recognised diploma for successful students" (Irish Press, 1952, p. 7). This echoes Chief RMS Professor John Dunne's recommendation to the Hospital Committee Board in 1949, that Grangegorman establish an occupational therapy training centre for external nursing students (Grangegorman Committee Minutes, 1949, p. 185). Although Dunne's proposal was submitted to the Minister for Health, there were no further references to it in subsequent Grangegorman Committee Minutes reviewed. In 1953, the IOTA organised an exhibition in the Mansion House of patients' work from occupational therapy departments in local hospitals including Grangegorman Mental Hospital (Irish Times, 1953).

\section{Therapeutic rationales $v$ s hospital management rationales}

There were conflicting rationales guiding the early occupational therapy practice in Grangegorman and the absence of patients' perspectives makes it difficult to assess its 
therapeutic value. Table II illustrates the range of occupational therapy activities referenced in the Committee Minutes reviewed. Underpinning therapeutic rationales are alluded to in the Visiting Committee Inspection Reports. References such as "air of contentment" (Inspector of Mental Hospitals, 1936, p. 19) and "homely spirit" (Grangegorman Visiting Committee, 1948, p. 361), highlight likely efforts to create a therapeutic environment:

In the therapy room they seemed a happy and contented lot, and before I left one of the patients sang a song and a really good singer she was (Portrane Visiting Committee, 1946, p. 257).

The Portrane Visiting Committee's (1948a, p. 210) observation that the male patients were "working away at various hobbies", highlights potential individual interest in occupational therapy activities. In the 1950s, a pattern of more creative and individual tasks emerged such as making children's felt toys (Grangegorman Visiting Committee, 1952, p. 1218), weaving a chequered black and white coat (Portrane Visiting Committee, 1953, p. 111) and constructing a small wardrobe (Grangegorman Visiting Committee, 1954, p. 257). In 1952, the Portrane Visiting Committee requested extra staff to assist with occupational therapy "in view of the importance of the work and of its beneficial effects on patients" (p. 978). Nurse Mary Fox's opinion in the Irish Independent (1953) is the only perspective from the nursing staff, which emerged in this documentary analysis. Her statement that occupational therapy's aim was to help patients "to do work, which was suitable for them and, where requested, to train them if possible in any occupation they would want", highlights efforts to encourage meaningful occupational engagement (Irish Independent, 1953, p. 8).

In contrast to these tentative therapeutic rationales, there were a range of hospital management and financial rationales underpinning the occupational therapy practice in Grangegorman. Underlining aims to the original introduction of occupational therapy in Grangegorman included stemming the hospital population growth "[...] the advantage of such clinics [. . . ] would lend to decrease the number of our insane" (Irish Times, 1937b, p. 5). Dr O'Conor Donelan's feedback to the Grangegorman Committee Board in 1934, that occupational therapy may be beneficial in "occupying and entertaining troublesome patients", highlights behavioural management objectives. Despite the introduction of occupational therapy, the Inspectors of Mental Hospital continued to report a large number of patients whom they described as "idle" (Inspector of Mental Hospitals, 1935, p. 20; 1937, p. 19) or "wandering aimlessly" (Inspector of Mental Hospitals, 1941, p. 18; 1942, p. 20). There appeared to be limited numbers of hospital patients engaged in the occupational therapy departments. The Inspector Mental Hospital reported 28 female patients engaged in occupational therapy in Portrane in 1941 and approximately 60 female patients engaged in Grangegorman Mental Hospital in 1943 (Inspector of Mental Hospital Report, 1941, 1943).

\begin{tabular}{ll}
\hline & Occupational therapy activities \\
\hline Brush-making & Mattress-making \\
Making flower pots & Darnin \\
Fretwork & Rubber mat-making \\
Knitting & Book-binding \\
Embroidering & Woodcrafts (e.g. making stools, tables and furniture) \\
Picture framing & Making trolley \\
Rug-making & Basket weaving \\
Wire work & Cushion making \\
Spinning & Weaving \\
Painting & Toy-making \\
\hline
\end{tabular}

Development of occupational therapy 77

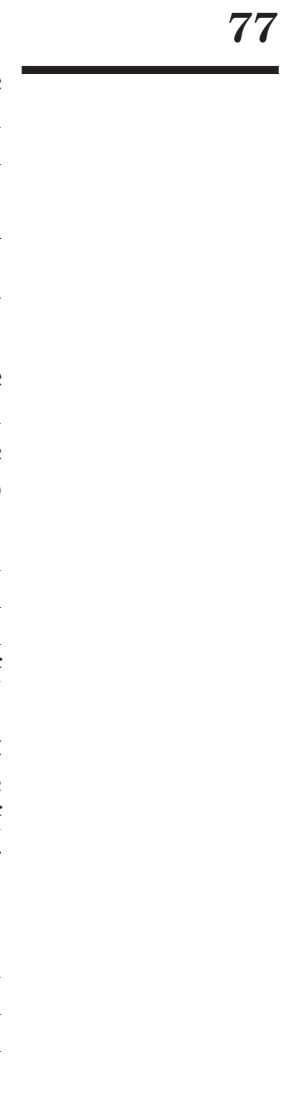

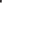

\footnotetext{
Table II.

Activities undertaken in the occupational therapy departments 1935-1954

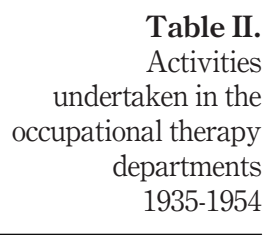


IJOT

48,1

The first reference of occupational therapy being expanded to ward level was in 1952 and then again in 1954 (Inspector of Mental Hospitals, 1952, 1954).

It is evident that some of the activities as listed in Table II, e.g. mattress-making and darning, were primarily beneficial for the general upkeep of the hospital. The perspective that occupational therapy was a form of work, rather than therapeutic engagement, was also expressed by patients themselves. In 1948, a request was made by patients engaging in occupational therapy for cigarettes, their reasoning being that "other working patients get them" (Portrane Visiting Committee, 1948b, p. 177). The surplus of work produced in the occupational therapy department was sold with "the profits arising from such sales to be lodged to credit of Canteen Account for the benefits of the patients" (Grangegorman Visiting Committee, 1936, p. 36). In 1952, a complaint was made by a patient to the Visiting Committee in relation to the selling of her handiwork made in the occupational therapy department without any reward for herself (Portrane Visiting Committee 1952a, p. 1249).

\section{Discussion}

\section{Establishment of occupational therapy in Grangegorman and Portrane}

This study shows that Grangegorman's introduction of occupational therapy parallels the process of occupational therapy's introduction in many British psychiatric hospitals, which were influenced by study tours of European psychiatric centres (Hall, 2016). Similar to the participants of the British RMPA study tours and Dr Eamon O'Sullivan (Hall, 2016; O'Sullivan, 1955), Grangegorman's sub-committee was also impressed with the occupational therapy practice in Santpoort Mental Hospital (originally derived from Dr Simon's principles), which emphasised ward level activity and handicraft workshops (Evans, 1929; Reynolds, 1992).

The subsequent sending of nursing staff to train in occupational therapy in Cardiff Mental Hospital signifies recognition by the Grangegorman Committee Board, of the need to create dedicated roles with specialised training to effectively introduce occupational therapy in the hospital. This is a comparable stance to that of the British Board of Control, 1933 Memorandum on Occupation Therapy for Mental Patients and that expressed in Eamon O'Sullivan's, 1955 Textbook of Occupational Therapy, although no specific training was sought for nursing staff at Killarney Mental Hospital (O'Sullivan, 1955, p. 17). The handicrafts organised in Grangegorman resemble handicrafts such as weaving, woodcrafts and needlework promoted in Killarney Mental Hospital, St. Patrick's Hospital and early occupational therapy practices within psychiatric hospitals internationally (Dunne et al., 2018b; O'Sullivan, 1955; Wilcock, 2002). Occupational therapy practice in mental health settings in the USA, the UK and Northern Europe stemmed largely from the psychiatry profession and this pattern was also observed in Grangegorman. While the contributions of RMS Dr O'Conor Donelan and later Chief RMS Professor John Dunne, do not appear as significant as that of Irish Occupational Therapy pioneering figures, Dr Eamon O'Sullivan or Dr Ada English, this study nevertheless highlights the importance of medical patronage in the development of occupational therapy in Grangegorman and Portrane Hospitals.

\section{Interface between short-course trained and diploma trained occupational therapists}

Occupational therapy in Grangegorman between 1934-1954 was overseen by nursing staff whom had undergone short training periods in a hospital setting. The employment of specifically trained nursing staff to deliver occupational therapy services was an internationally common practice in psychiatric hospitals in the beginning decades of occupational therapy's professionalisation (Hall, 2016; Quiroga, 1995; Webb, 2002; Wilcock, 2002). In his review of mental health nursing in the 1930s' institutional culture, McCrae 
(2014) argues that while nursing staff had a good understanding of patients, they were "not always able to fulfil the potential of occupational therapy" (p. 80). This study adds to research, which highlights the complexities of professional identity, recognition and role boundaries during the early emergence of the occupational therapy profession in Ireland (Dunne et al., 2018a; Lynch and Pettigrew, 2014).

As highlighted in this study, members of Grangegorman occupational therapy staff played key roles in the establishment of the IOTA. There appeared to have been tensions between the short-course trained IOTA members and the AOT (whose members had undergone the professional three year diploma). This was alluded to in Fanning's (1951) letter to the Irish Independent in which he makes reference to the late invitation to the London AOT Congress, which subsequently prevented any IOTA member from attending the conference. The distinction between the diploma-trained occupational therapists and the early short-course trained IOTA members also carried through to the 1965 establishment of the AOTI (Fleming, 1986). The AOTI only became aware of the IOTA when trying to register their name and learnt that "there was already a company registered as the "Irish Association of OT's", which, in turn, "caused consternation among the qualified OT's" (Association of Occupational Therapists of Ireland, 2015, p. 1). The AOTI became a member of WFOT in 1970, thus giving credence to their status as the Irish professional body for occupational therapy (Association of Occupational Therapists of Ireland, 2019). Furthermore, while the IOTA had initially aimed to develop an occupational therapy training school (Irish Press, 1951), they did not play any role in the formation of St. Joseph's College of Occupational Therapy, Dún Laoghaire, Co. Dublin in 1963 and the organisation disbanded in 1975 (Dunne, 2017). This tension between early hospital trained occupational therapists and diploma qualified occupational therapists is in line with Dunne et al.'s (2018b) oral history research, which found evidence of discordant relationships and efforts by the St. Joseph's College of Occupational Therapy graduates to differentiate their practice from that of the early occupational therapy workers by avoiding craft activities and focussing on the purposeful and directed use of activity.

\section{Therapeutic rationales $v$ s hospital management rationales}

Without the perspectives of the patients themselves, it is impossible to draw any definite conclusions on the therapeutic or non-therapeutic nature of early occupational therapy in Grangegorman or Portrane Hospital. Nurse Mary Fox's quote in the Irish Independent (1953) provides a glimpse of the rationale behind the hospitals' occupational therapy practice. She highlights the importance of choosing work suitable for the patient, suggesting a consideration of patients' ability - a concept raised in Eleanor Clarke Slagle's, 1934 lecture. Mary Fox mentions providing training to patients "if possible in any occupation they would want" (Irish Independent, 1953, p. 8), illustrating an attempt to provide choice within the institutional constraints. The Visiting Committees reported favourably on the activity engagement and atmosphere in occupational therapy departments, reflecting a generally positive viewpoint of "the importance of the work and of its beneficial effects on patients" (Portrane Visiting Committee, 1952b, p. 978). However, caution is required in interpreting these reports due to possible external pressures to present a picture of effective therapeutic treatment (Prior, 2004).

Alongside allusions to the possible therapeutic benefits, it is clear that occupational therapy activities were also used to support with hospital management and finances. RMS Dr O'Conor Donelan's feedback to the Grangegorman Committee Board in 1934 that occupational therapy may be beneficial to both "patients and institutions" (O'Conor Donelan, 1934, p. 589), highlights the co-existence of individual patient needs and institutional needs. This co-existence and the
Development of occupational therapy 
IJOT

48,1

promotion of work activities were similarly prominent in early occupational therapy practice in public psychiatric hospitals in Ireland and the UK (Hall, 2016; McCrae and Nolan, 2016; O'Sullivan, 1955). Eamon O'Sullivan's use of patient labour when building a local football stadium and when allowing patients to work in nurses' homes has also been viewed as contradictory to his emphases on keeping the therapeutic aspect of occupation to the fore (Pettigrew et al., forthcoming). In his book on the history of psychiatry in Ireland, Kelly (2016) highlights the difficulty in ensuring "patient work was genuinely therapeutic" and not just necessary labour required for the hospital to function (p. 181). The tensions between therapeutic and hospital management rationales can be further contextualised with consideration of the ongoing economic austerity and limited State financial provision to Irish mental healthcare (Killeen, 2012; Kelly, 2016). There is evidence that patients themselves viewed occupational therapy as work, as suggested through their request for cigarettes (Portrane Visiting Committee, 1948b). The therapeutic value of work has long been recognised by the occupational therapy discipline (Harvey-Krefting, 1985). However, without the patients' own perspectives on the work they were carrying out, it is impossible to assess the meaning, purpose and value - all core concepts of today's occupational therapy (Hinojosa et al. 2017) - of Grangegorman's occupational therapy practice.

Another contradiction to the therapeutic aims of occupational therapy in Grangegorman was the large number of patients who remained unengaged. Although work (e.g. in the kitchen, laundry and farms) and recreational occupations (e.g. cinema and football) were continually promoted at a hospital level (Inspector of Mental Hospital, 1936, 1954), there continued to be limited opportunities for occupational engagement for large numbers of patients. Findings in this study show the number of patients engaged in each occupational therapy department ranged between 15 to 60 people. The combined population of Portrane and Grangegorman in the time period studied rose to over 3,500 (Reynolds, 1992), representing a significant deviation from the special sub-committee's original aim in 1934 of engaging about 90 per cent of its hospital patients in occupational therapy (Irish Independent, 1934). This was also a deviation from other contemporary national and international occupational therapy practices where occupational therapy was provided for large numbers of patients (Board of Control, 1933; Pettigrew et al., 2017).

Unlike similar American institutions (Barker Schwartrz, 2003; Quiroga, 1995) there was little evidence in Grangegorman of other therapeutic interventions such as vocational skills or habit-training to support the discharge of patients (Bing, 1981). This may in part be explained by the predominance of the institutional model of care within Irish mental health services from the nineteenth to early twentieth century, stemming from social, political and economic factors (Brennan, 2014; Kelly, 2016). The very limited material available on people's experiences of Irish psychiatric hospitals in the early to mid-twentieth century have often presented a bleak picture of disempowerment and oppression, in overcrowded and dire hospital conditions (Avis, 1964; Grealy, 2008). These perspectives allude to experiences of occupational deprivation, which describes the preclusion from opportunities to engage in meaningful occupations because of factors beyond individual control (Whiteford, 2000). Therefore, while early occupational therapy in Grangegorman can be seen as making efforts to improve patients' lives within the hospital, these efforts were limited by the institutional settings patients found themselves in, with distant prospects of discharge (Kelly, 2016).

\section{Areas for further research}

Further research is required to gain a deeper understanding of the development of occupational therapy in mental health services in Ireland during the early to mid-twentieth century. Dr O'Conor Donelan's attendance at the 1934 London Conference of occupational 
therapy, where Eleanor Clarke Slagle and Elizabeth Casson were guest speakers, signifies a direct influence of British and American pioneering occupational therapy figures on the development of occupational therapy in Grangegorman. This adds to knowledge of the correspondence between the Irish and American Occupational Therapy disciplines, as evidenced by Dr William Rush Dunton's foreword in Eamon O'Sullivan's, 1955 A Textbook of Occupational Therapy. Research is required to further examine the link between Irish and international occupational therapy pioneers.

On reviewing later Grangegorman Committee Minutes (1960, p. 5), a reference was found

Development of occupational therapy for the application for "a Trained Occupational Therapist" in Grangegorman. No further information was available, however; the hospital was clearly keen to use a qualified occupational therapist as Grangegorman staff member, William Field, was among the first cohort of St. Joseph's College of occupational therapy graduates. Research is ongoing to establish the beginning of professional occupational therapy in Grangegorman hospital (becoming St. Brendan's Hospital in 1958), in the emerging context of the nationwide decline of Irish institutions from the mid-1960s onwards (Kelly, 2016). Edward Fanning remained chairman of the IOTA until 1956 (Foy, 1963), however, additional research is required to understand the demise of the association. Further critical reflection on the transition period from the early occupational therapy era to the era of professional diploma qualified occupational therapists is merited and may help contextualise a better understanding of interdisciplinary relationships in mental health care today. It is also important that further archival and oral history is undertaken to better understand and acknowledge patients' personal experiences of psychiatric hospitals and to learn how we as a society can do better (Cavalli et al., 2019; Kelly, 2016).

\section{Limitations}

The HSE ethical restrictions limiting full access to 11 years of Committee Minutes (Table I), mean there are inevitable gaps of knowledge in this study (Ahmed, 2010). McDowell (2002) argues that historical documents may conceal as much as they reveal. The Committee Minutes, Inspection Reports and newspaper archives analysed, therefore, present only part of the picture of the early occupational therapy practice in Grangegorman. The limited evidence portraying the nursing staff's point of view means it has not been possible to gain insight into the six month training course provided in Cardiff Mental Hospital. This will be the focus of future research as it will provide a better understanding of the occupational therapy programmes undertaken in Grangegorman and Portrane.

Arguably, the most significant limitation in this study is the notable absence of patients' experiences of occupational therapy. The narrative voice and subsequent perspectives of patients in Grangegorman would have provided invaluable information on the nature of early occupational therapy practice in Grangegorman and Portrane.

Similar to occupational therapy practices in other contemporary Irish hospitals (Dunne et al., 2018b), there appears to be limited attention from Grangegorman's occupational therapy practitioner's to issues of institutional power and patients' rights. Townsend and Wilcock (2004, p. 75) argue that "silence implies compliance with the status quo". However, occupational therapy was a new, emergent healthcare practice in the mid-twentieth century Ireland. It was dependent on medical patronage and institutional hierarchies and its practitioners were nurses who were already embedded in an institutional structure, which emphasised the distance between staff and patients (Sheridan, 2005). Sheridan states that nurses during this era were 'institutional agents' who "ensured that patients adhered to the prevailing system of rules and regulations" (Sheridan, 2005, p. 178). This precluded attention to questions of institutional power and patient rights (Saks, 2009), which have recently 
IJOT

48,1

received in-depth attention in occupational therapy (Hammell and Iwama, 2012; Galheigo, 2011; Whiteford and Hocking, 2011).

\section{Conclusion}

History provides a contextual insight into the past and nurtures an understanding for how present events emerged (McDowell, 2002). This study maps the first 20 years (1934-1954) of occupational therapy's development in Grangegorman Mental Hospital and its auxiliary hospital, Portrane Mental Hospital, as described in publically available hospital archives, governmental documents and newspaper archives. The establishment of occupational therapy in Grangegorman and Portrane was influenced by hospital figures' exposure to international occupational therapy practice. Along with other recent work (Dunne et al., 2018b; Lynch and Pettigrew, 2014; Pettigrew et al., 2017; Prendiville and Pettigrew, 2015), this study throws light on the early practitioners of occupational therapy, who have been largely excluded from the predominant narrative of the history of occupational therapy practice in Ireland (Pettigrew et al., forthcoming). The role of specially trained nursing staff in the provision of occupational therapy in Grangegorman and in the establishment of the IOTA, throws light on the complexities of occupational therapy's role origins in mid-twentieth century Ireland.

\section{Notes}

1. Ireland in this study refers to the Republic of Ireland alone, it does not explore the history of occupational therapy in Northern Ireland.

2. Early twentieth Century terminology (such as asylum, mental hospital and patient) has been retained to ensure fidelity to the historical sources.

3. The Economic War was a retaliatory trade war between the Irish Free State and the UK from 1932-1938, which led to increased economic hardship in Ireland (Killeen, 2012).

\section{References}

Ahmed, J.U. (2010), "Documentary research method: new dimensions", Indus Journal of Management and Social Sciences, Vol. 4 No. 1, pp. 1-14.

Anderson, L.T. and Reed, K.L. (2017), The History of Occupational Therapy: The First Century, 1st ed., SLACK Inc., Thorofare, NJ.

Association of Occupational Therapists of Ireland (2015), “The AOTI archives January 2015”, available at: www.aoti.ie/page.aspx?contentid=5601\# (accessed 12 April 2016).

Association of Occupational Therapists of Ireland (2019), "About us", available at: www.aoti.ie/aboutus (accessed 4 October 2019).

Avis, R. (1964), "I'm Very Fond of Holywell but ... a Constructive Criticism, Speedwell, p. 36", in McClelland G., "Speedwell Magazine: An insider view of Holywell Psychiatic Hospital Antrim, 1959-1973”, in Prior, P.M. (Ed.), Asylums, Mental Health Care and the Irish 1800-2010, Irish Academic Press, Dublin, pp. 44-73.

Barker Schwartrz, K. (2003), "History of occupation", in Kramer, P., Hinojosa, J. and Brasic Royeen, C. (Eds), Perspectives in Human Occupation: Participation in Life, Lippincott Williams and Wilkins, Philadelphia, PA, pp. 18-31.

Berger, R. (2013), “Now I see it, now I don't: researcher's position and reflexivity in qualitative research", Qualitative Research, Vol. 15 No. 2, pp. 219-234.

Bing, R.K. (1981), "Eleanor clarke slagle lectureship - 1981. Occupational therapy revisited: a paraphrastic journey", American Journal of Occupational Therapy, Vol. 35 No. 8, pp. 499-518. 
Board of Control (1933), Memorandum on Occupation Therapy for Mental Patients, H.M. Stationary Office, London.

Braun, V. and Clarke, V. (2006), "Using thematic analysis in psychology", Qualitative Research in Psychology, Vol. 3 No. 2, pp. 77-101.

Brennan, D. (2014), Irish Insanity: 1800-2000, Routledge, Oxon.

Cavalli, V., Hegarty, R. and Kelly, B. (2019), "Report on Historical Mental Health Records Seminar", Royal Irish Academy, (accessed 16 May 2019).

Clarke Slagle, E. (1934), "Occupational therapy notes: London conference on occupational therapy", Occupational Therapy and Rehabilitation, Vol. 13 No. 5, pp. 351-352.

Cohen, L., Manion, L. and Morrison, K. (2007), Research Methods in Education, 6th ed, Routledge, New York, NY.

Dunne, B. (2017), "From the wretched laundry to a lovely solarium: the history of the therapeutic use of occupation in Ireland, 1863-1970", $\mathrm{PhD}$ thesis, University of Limerick.

Dunne, B., Pettigrew, J. and Robinson, K. (2015), "Using historical documentary methods to explore the history of occupational therapy”, British Journal of Occupational Therapy, Vol. 79 No. 6, pp. 376-384.

Dunne, B.D., Pettigrew, J. and Robinson, K. (2018a), “An oral history of occupational therapy education in the republic of Ireland", British Journal of Occupational Therapy, Vol. 81 No. 12, pp. 717-726.

Dunne, B.D., Robinson, K. and Pettigrew, J. (2018b), “A case study of the development of occupational therapy at St. Patrick's hospital Dublin, 1935-1969”, Irish Journal of Occupational Therapy, Vol. 46 No. 1, pp. 31-45.

Evans, A.E. (1929), "Report on the RMPA study tour of holland", Journal of Mental Science, Vol. 75 No. 308, pp. 192-198.

Fanning, E.C. (1951), “Therapy conference (letter to editor)”, Irish Independent, 26 June, p. 3.

Ferriter, D. (2004), The Transformation of Ireland 1900, 2000, Profile Books Ltd., London.

Fleming, D.M. (1986), "Twenty one years of the association”, available at: https://aoti.ie/page.aspx? contentid=30 (accessed 23 May 2016).

Foy, M. (1963), "People of Ireland: Edward C. Fanning of Waterford”, Irish Times, (accessed 19 March 19), p. 6.

Friedland, J. (2011), Restoring the Spirit: The Beginnings of Occupational Therapy in Canada, 18901930, McGill-Queen's University Press, Montreal.

Fuller Torrey, E. and Miller, J. (2001), The Invisible Plague: The Rise of Mental Illness from1750 to the Present, Rutgers University Press, NJ.

Galheigo, M.S. (2011), "What needs to be done? Occupational therapy responsibilities and challenges regarding human rights", Australian Occupational Therapy Journal, Vol. 58 No. 2, pp. 60-66.

Gibney, J. (2017), A Short History of Ireland, 1500-2000, Yale University Press, New Haven.

Grangegorman Committee Minutes (1935), Grangegorman Mental Hospital Committee Minutes 1935, Grangegorman Mental Hospital, Dublin.

Grangegorman Committee Minutes (1949), Grangegorman Mental Hospital Committee Minutes 1949, Grangegorman Mental Hospital, Dublin.

Grangegorman Committee Minutes (1960), Grangegorman Mental Hospital Committee Minutes 1960, Grangegorman Mental Hospital, Dublin.

Grangegorman Visiting Committee (1936), "Inspection report: Grangegorman 9th november in Grangegorman Mental Hospital Committee Minutes 1936”, Grangegorman Mental Hospital, Dublin, p. 36. 
IJOT

48,1

Grangegorman Visiting Committee (1948), "Inspection report: Grangegorman 2nd November in Grangegorman Mental Hospital Committee Minutes 1948”, Grangegorman Mental Hospital, Dublin, pp. 335-337.

Grangegorman Visiting Committee (1952), "Inspection report: Grangegorman 1st july in Grangegorman Mental Hospital Committee Minutes 1952”, Grangegorman Mental Hospital, Dublin, pp. 256-257.

Grangegorman Visiting Committee (1954), "Inspection report: Grangegorman 7th september in Grangegorman Mental Hospital Committee Minutes 1954”, Grangegorman Mental Hospital, Dublin, pp. 1144-1145.

Grealy, H. (2008), Bird Nest's Soup, Cork University Press, Cork.

Hall, J. (2016), "From work and occupation to occupational therapy: the policies of professionalization in english mental hospitals from 1919 to 1959", in Ernst, W. (Ed.), Work, Psychiatry and Society, Manchester University Press, Manchester, pp. 314-333.

Hammell, K.R.W. and Iwama, M.K. (2012), "Well-being and occupational rights: an imperative for critical occupational therapy”, Scandinavian Journal of Occupational Therapy, Vol. 19 No. 5, pp. 385-394.

Harvey-Krefting, L. (1985), "The concept of work in occupational therapy: A historical review", American Journal of Occupational Therapy, Vol. 39 No. 5, pp. 301-307.

Higgs, J., Andresen, L. and Fish, D. (2004), "Practice knowledge - its nature, sources and contexts", in Higgs, J., Richardson, B and Dahlgren, M.A. (Eds), Developing Practice Knowledge for Health Professionals, Butterworth-Heinemann, Edinburgh, pp. 51-69.

Hinojosa, J., Kramar, P., Royeen, C.B. and Luebben, A. (2017), "The core concept of occupation", in Hinojosa, J., Kramar, P. and Royeen, C.B. (Eds), Perspectives on Human Occupation: Theories Underlying Practice, 2nd ed., F.A. Davis Company, Philadelphia, PA, pp. 23-38.

Inspector of Mental Hospitals (1935), "Annual report for the inspector of mental hospitals for the year 1935”, Stationary Office, Dublin.

Inspector of Mental Hospitals (1936), "Annual report for the inspector of mental hospitals for the year 1936”, Stationary Office, Dublin.

Inspector of Mental Hospitals (1937), "Annual report for the inspector of mental hospitals for the year 1937”, Stationary Office, Dublin.

Inspector of Mental Hospitals (1941), "Annual report for the inspector of mental hospitals for the year 1941”, Stationary Office, Dublin.

Inspector of Mental Hospitals (1942), "Annual report for the inspector of mental hospitals for the year 1942", Stationary Office, Dublin.

Inspector of Mental Hospitals (1943), "Annual report for the inspector of mental hospitals for the year 1943”, Stationary Office, Dublin.

Inspector of Mental Hospitals (1952), "Annual report for the inspector of mental hospitals for the year 1952", Stationary Office, Dublin.

Inspector of Mental Hospitals (1954), "Annual report for the inspector of mental hospitals for the year 1954”, Stationary Office, Dublin.

Irish Free State. Department of Foreign Affairs (1934), Investigations into Conditions of Mental Hospitals and Clinics in Holland, Health Matters, Series 31/121, Department of Foreign Affairs, Dublin.

Irish Independent (1934), "Work for mental patients: clinics and new hospital recommended. Committee's report”, 15 December, p. 8.

Irish Independent (1951), "Irish girl at therapist congress”, 15 June, p. 3.

Irish Independent (1953), "Occupational therapy company is formed", 18 June.

Irish Press (1934), "Mental clinics proposal: Interesting report of Grangegorman Committee”, 15 December, p. 9. 
Irish Press (1951), “Occupational therapy”, 30 April, p. 7.

Irish Press (1952), "News in brief: occupational therapy”, 12 March, p. 7.

Irish Times (1930), "Scheme to combat tuberculosis: Village settlement near Dublin 12 September, p. 8.

Irish Times (1937a), "Care of the Insane: big increase in expenditure, the Grangegorman estimates", 11 January, p. 8.

Irish Times (1937b), "Social service an investment: Municipal Delegates Appeal to Government”, 16 September, p. 5.

Irish Times (1953), “Hospital patients' exhibition”, 27 April, p. 5.

Kelly, B. (2007), "One hundred years ago: the richmond asylum, Dublin in 1907”, Irish Journal of Psychological Medicine, Vol. 24 No. 3, pp. 108-114.

Kelly, B. (2014), Ada English: Patriot and Psychiatrist, Irish Academic Press, Newbridge.

Kelly, B. (2016), Hearing Voices: The History of Psychiatry in Ireland, Irish Academic Press, Newbridge.

Kielhofner, G. (2009), Conceptual Foundations of Occupational Therapy Practice, FA Davis, Philadelphia, $\mathrm{PA}$.

Killeen, R. (2012), A Brief History of Ireland: Land, People, History, Constable and Robinson Ltd., London.

Lusk, B. (1997), "Historical methodology for nursing research", Image: The Journal of Nursing Scholarship, Vol. 29 No. 4, pp. 355-360.

Lynch, S. and Pettigrew, J. (2014), "It sowed a seed': ethe professional experiences of occupational therapists who started working in the republic of Ireland in the 1970s", Irish Journal of Occupational Therapy, Vol. 41 No. 1, pp. 30-35.

McCrae, N. (2014), "Resilience of institutional culture: mental nursing in a decade of radical change", History of Psychiatry, Vol. 25 No. 1, pp. 70-86.

McCrae, N. and Nolan, P. (2016), The Story of Nursing in British Mental Hospitals: Echoes from the Corridors, Routledge, Oxon.

McDowell, W.H. (2002), Historical Research: A Guide, Pearson Education Ltd., Harlow.

O’Brien, C. (2013), “Goodbye grangegorman”, Irish Times, 26 February, p. 17.

O’Conor Donelan, J. (1934), “Joint committee:19th july 1934 Grangegorman Mental Hospital Committee Minutes 1934", Grangegorman Mental Hospital, Dublin, p. 589.

O'Conor Donelan, J. (1935), "Letter to medical superintendant Dr McCowan in Grangegorman Mental Hospital Committee Minutes 1935”, Grangegorman Mental Hospital, Dublin, p. 35.

O’Malley, K. (1988), “Introduction”, in O'Brien, E., Browne, L. and O'Malley, K. (Eds), The House of Industry Hospitals 1772-1987, The Richmond, Whitworth and Hardwicke (St. Laurence's Hospital), Dublin, Anniversary Press, pp. 1-21.

O'Shea, B. and Falvey, J. (1996), "A history of the richmod asylum (St. Brendan's hospital)", in Freeman, H. and Berrios, G.E. (Eds), 150 Years of British Psychiatry, Vol II: The Aftermath, Athlone Press Ltd., London, pp. 407-433.

O'Sullivan, E. (1955), A Textbook of Occupational Therapy, with Chief Reference to Psychological Medicine, HK Lewis and Co. Ltd., London.

Payne, G. and Payne, J. (2004), Key Concepts in Social Research, SAGE Publications, London.

Peloquin, S.M. (1989), "Moral treatment: contexts considered", American Journal of Occupational Therapy, Vol. 43 No. 8, pp. 537-544.

Peloquin, S.M. (1991a), "Occupational therapy service: individual and collective understandings of the founders, part 1”, American Journal of Occupational Therapy, Vol. 45 No. 4, pp. 352-360.

Peloquin, S.M. (1991b), "Occupational therapy service: individual and collective understandings of the founders, part 2”, American Journal of Occupational Therapy, Vol. 45 No. 8, pp. 733-744. 
IJOT

48,1

Pettigrew, J., Robinson, K., Dunne, B. and O'Mahoney, J. (2017), "Major trends in the use of occupation as therapy in Ireland 1863-1963”, Irish Journal of Occupational Therapy, Vol. 45 No. 1, pp. 4-14.

Pettigrew, J. Shalvey, A. Dunne, B. and Robinson, K. (forthcoming), “Eamon O'Sullivan: 20th century psychiatrist and occupational therapy patron", History of Psychiatry.

Portrane Visiting Committee (1946), "Inspection report: Portrane 16th september Grangegorman Mental Hospital Committee Minutes 1946", Grangegorman Mental Hospital, Dublin, pp. 257-258.

Portrane Visiting Committee (1948a), "Inspection report: Portrane 19th July", in Grangegorman Mental Hospital Committee Minutes 1948, Grangegorman Mental Hospital, Dublin, pp. 208-212.

Portrane Visiting Committee (1948b), "Inspection report: Portrane 8th June" in Grangegorman Mental Hospital Committee Minutes 1948, Grangegorman Mental Hospital, Dublin, pp. 176-178.

Portrane Visiting Committee (1952a), "Inspection report: Portrane 29th May" in Grangegorman Mental Hospital Committee Minutes 1952, Grangegorman Mental Hospital, Dublin, p. 1249.

Portrane Visiting Committee (1952b), "Inspection report: Portrane 8th January" in Grangegorman Mental Hospital Committee Minutes 1952, Grangegorman Mental Hospital, Dublin, p. 978.

Portrane Visiting Committee (1953), "Inspection report: Portrane 30th April" in Grangegorman Mental Hospital Committee Minutes 1953, Grangegorman Mental Hospital, Dublin, pp. 108-111.

Prendiville, C. and Pettigrew, J. (2015), "Leisure occupations in the Central criminal lunatic asylum: 1870-1920", Irish Journal of Occupational Therapy, Vol. 43 No. 1, pp. 12-19.

Prior, P.M. (2004), "Prisoner or patient? The official debate on the criminal lunatic in nineteenth-century Ireland", History of Psychiatry, Vol.15 No. 2, pp. 177-192.

Quiroga, V.A. (1995), Occupational Therapy History: The First 30 Years, 1900 to 1930, American Occupational Therapy Association, Bethesda, MD.

Reynolds, J. (1992), Grangegorman: Psychiatric Care in Dublin since 1815, Institute of Public Administration in association with Eastern Health Board, Dublin.

Saks, M. (2009), "Leadership challenges: professional power and dominance in healthcare", in Bishop, V. (Ed.), Leadership in the Healthcare Professions, OPU/McGrawhill, Maidenhead, Berkshire, pp. 52-74.

Salkind, N.J. (2010), Encyclopedia of Research Design, SAGE Publications Inc., Thousand Oaks, CA.

Scott, J. (1990), A Matter of Record: Documentary Sources in Social Research, John Wiley and Sons, Cambridge.

Sedgwick, A., Cockburn, L. and Trentham, B. (2007), "Exploring the mental health roots of occupational therapy in Canada: a historical review of primary texts from 1925-1950", Canadian Journal of Occupational Therapy. Revue Canadienne D'Ergotherapie, Vol. 74 No. 5, pp. 407-418.

Sheridan, A. (2005), "Being a psychiatric nurse in irelandin the 1950s", in Fealy, G.M. (Ed.), Care to Remember: Nursing and Midwifery in Ireland, Mercier Press, Cork, pp. 172-184.

Townsend, E. and Wilcock, A.A. (2004), "Occupational justice and client centred practice: a dialogue in progress", Canadian Journal of Occupational Therapy, Vol. 71 No. 2, pp.75-87.

Walsh, D. (1968), "Hospitalized psychiatric morbidity in the republic of Ireland", British Journal of Psychiatry, Vol. 114 No. 506, pp. 11-14.

Webb, K.A. (2002), From County Hospital to NHS Trust: The History and Archives of NHS Hospitals, Services and Management in York, 1740-2000, Volume 1: History, Borthwick Publications, New York, NY.

Whiteford, G. (2000), "Occupational deprivation: global challenge in the new millennium", British Journal of Occupational Therapy, Vol. 63 No. 5, pp. 200-204.

Whiteford, G.E. and Hocking, C. (Eds) (2011), "Occupational science: society", Inclusion, Participation, Blackwell Publishing Ltd, Sussex. 
Wiener, J.A. and Gilliland, A.T. (2011), "Balancing between two goods: health insurance portability and accountability act and ethical compliancy considerations for privacy-sensitive materials in health sciences archival and historical special collections", Journal of the Medical Library Association: Jmla, Vol. 99 No. 1, pp. 15-22.

Development of occupational therapy

Wilcock, A.A. (2002), Occupation for Health: Vol. 2: A Journey from Prescription to Self Health, British Association and College of Occupational Therapists, London.

World Federation of Occupational Therapists (2019), "History", available at: www.wfot.org/AboutUs/ History.aspx (accessed 4 October 2019).

Corresponding author

Rebecca Cahill can be contacted at: rebecca.cahill@hse.ie

For instructions on how to order reprints of this article, please visit our website: www.emeraldgrouppublishing.com/licensing/reprints.htm Or contact us for further details: permissions@emeraldinsight.com 